Article

\title{
Examining the Moderating Role of Brand Loyalty among Consumers of Technology Products
}

\author{
Sunder Ramachandran ${ }^{1, *(1)}$ and Sreejith Balasubramanian ${ }^{2}$ (i) \\ 1 Abu Dhabi School of Management, P.O.Box 6844, Abu Dhabi, UAE \\ 2 Business School, Middlesex University Dubai, P.O.Box 500697, Dubai, UAE; s.balasubramanian@mdx.ac.ae \\ * Correspondence: sunderrama@gmail.com
}

Received: 14 October 2020; Accepted: 25 November 2020; Published: 28 November 2020

\begin{abstract}
The long-term survival of a company depends on its economic sustainability. It costs several times more to acquire new customers than retain current ones, and loyal customers spend more than new ones. Unfortunately, consumers are increasingly becoming less loyal to brands/products than before. Unearthing the underlying reasons for this diminishing consumer loyalty is critical. This forms the motivation of this study, which aims to examine the moderating role of loyalty among consumers of technology products. Specifically, the study explores the heterogeneity in the factors (antecedents) influencing brand-loyal attitudes and behavior among consumers of different loyalty levels. A total of 355 survey responses were obtained from an administrated survey across three loyalty groups (high loyalty—155; medium loyalty—99; low loyalty-90) in the United Arab Emirates. Structural equation modeling and multi-group moderation tests were used to test the hypothesized differences in the relationships between antecedents (trust, self-image, quality, and perceived ease of use) and customer attitude, and between customer attitude and repurchase intentions among the different loyalty groups. The results show that the different levels of loyalty have a moderating impact on the relationships. The findings are useful for marketers to better understand and manage customer attitudes, and subsequent purchase/repurchase intention depending on the levels of loyalty they may be in, as well as maneuver their customers through the different levels of loyalty to achieve business sustainability.
\end{abstract}

Keywords: business sustainability; brand loyalty; consumer behavior; repurchase intention; technology products; structural equation modeling

\section{Introduction}

As the saying goes, the business of business is to stay in business [1]. In today's highly competitive global market, one of the main challenges for organizations is to ensure business sustainability or the preservation of a business through time. Sustainability in marketing literature covering different aspects, such as sustainable reputation [2], sustainable brand management [3], sustainable online customers [4], and sustainable brand loyalty [5], has witnessed significant interest in recent years. Among these interrelated aspects, brand loyalty has emerged as a critical factor for sustainable business growth as it directly contributes to increased market share and profitability $[6,7]$. This is because, sustainable business, at a basic level, is to make sure that customers are satisfied and become loyal to the brand. In other words, maintaining a loyal customer base is critical for business sustainability. The importance of sustainability has never been more pronounced than in these pandemic times. The pandemic continues to ensnare almost every possible area, leaving a deleterious effect in its wake. As the world struggles to come to grips with this seemingly unending menace, one of the foremost thoughts in the minds of business owners is not just immediate survival but also continued sustenance. Businesses are vying more aggressively to grab a share of the customers' wallet and exert their best 
efforts to bring back the lost customers into their fold. This emphasizes the critical role played by brand loyalty in the survival and sustainability of businesses. Brand-loyal behavior is the overt act of selective repeat purchasing based on evaluative psychological decision processes, while brand-loyal attitudes are underlying predispositions to behave in such a selective fashion [8,9]. A loyal customer is committed to their product/firm and is less price-sensitive and less prone to other enticements $[10,11]$. In other words, loyal customers are like the proverbial "bird in hand", that costs less to retain than to attract a new one [12]. Moreover, they are willing advocates of the product/firm, and thereby, provide one of the most effective and inexpensive forms of advertisements.

However, recent studies have shown that firms are losing loyal customers faster today to competition than before, given the highly crowded marketplace seeking to grab the attention of the promiscuous consumer with myriad and less differentiated product offerings [13]. A more recent industry study on consumer loyalty has shown that nearly two-fifths of consumers feel less loyal to brands and companies than a year ago [14]. Yet, this feeling is belied by our continued support for the brands we know and trust. Brand-loyal attitudes and behavior is, therefore, an increasingly more complicated problem than before, and it is important that we consider it as a dynamic and non-linear process rather than viewing it as simple, straightforward, or even linear as it may lead to erroneous conclusions [9].

Though brand loyalty has been extensively studied over many decades, the focus of the studies has been mostly on understanding its direct and mediating role in consumer behavior. Despite increasing calls in the literature, the moderating impact of brand loyalty on the consumer acceptance of a product/service has witnessed very limited empirical investigation $[9,15,16]$. For instance, it is important to understand the heterogeneity in the antecedents (e.g., trust, quality) in forming/modifying customer attitudes and subsequent purchase/repurchase intention as consumers move through the different levels of loyalty, i.e., from no/low loyalty to high loyalty [16]. This understanding would enable firms to assess how much time, money, and effort they should invest and where to invest to achieve the desired attitudes towards the product/brand of customers belonging to different loyalty segments. Further, it also helps in understanding whether the loyal customer base is still a holy grail in today's fast-changing, competitive, technology-driven world, and if so, whether brands can take their loyal customer base for granted and even exploit them?

The relevance of such understanding is even greater for technology products such as smartphones and tablets, which are having increasingly shorter life-cycles. Recent evidence has shown that firms with a loyal customer base are exploiting the trust of their customers. For example, consider the case of Apple, which was accused of deliberately slowing down their old iPhones in an attempt to make customers buy new ones. This scandalous practice of "throttling", which came to be known as "battery gate", led to customers feeling cheated and angry and resulted in more than 60 lawsuits being filed against Apple [17]. Similarly, the Volkswagen Group, one of the leading car manufacturers in the world, has openly admitted that they broke the trust of their customers and the general public in the emission scandal, where they used illegal software to cheat on emissions tests [18]. Similarly, Facebook has publicly apologized for the "breach of trust" with consumer data in the Cambridge Analytica scandal. Yet, these brands emerged stronger from these scandals and retained their position or became leaders in their respective categories.

From a product quality perspective, Samsung, another brand with a loyal customer base, experienced a considerable quality setback with its Note7 smartphone. Within weeks of its launch, Samsung's South Korean customers complained about its battery exploding and catching fire, causing a colossal loss of USD 26 billion in the stock market and an estimated USD 16 billion in sales [19]. Like Apple, Samsung also managed to emerge stronger, and became a leader in the smartphone market.

Similarly, in terms of ease of use, Instagram has undergone several updates and layout changes in recent years, which did not fare well with their users, with many active users openly expressing their brand hate against these new updates and changes [20]. Yet, Instagram users have grown significantly, with many users even switching from other social media platforms such as Facebook to Instagram [21]. 
Finally, recent studies have shown that brands are missing out on billions of dollars by failing to take a balanced approach to marketing campaigns that supports, rather than undermines, the self-image of all demographic groups [22]. For instance, H\&M has been accused of racially insensitive advertisements, such as the "monkey sweatshirt", that hurt the self-image of a particular demographic group [23]. Unlike technology brands, this scandal, which H\&M publicly apologized for, had led to a significant decline in their sales $[24,25]$. However, it is unknown whether this self-image congruence on brand preference is similar across different loyalty groups of technology brands? This understanding is critical for technology brands in their effort to develop or maintain self-image to attract new customers or retain existing customers.

In short, the above examples raise the following question: Had these episodes that affected trust, quality, ease of use, and self-image occurred with a recent entrant (in low customer loyalty segment) in the technology product category, would that have affected their customer attitude and subsequent purchase intention more adversely than for customer segments in medium and high loyalty?

This formed the motivation of this study, which aims to understand the impact of antecedents, namely, trust, quality, perceived ease of use, and self-image on attitude towards the brand and subsequent repurchase intention across different customer loyalty (high, medium, and low loyalty) groups. The findings have great significance for marketers in understanding and in devising strategies for converting low loyalty groups to high loyalty groups.

The rest of the paper is structured as follows. In Section 2, the relevant literature on brand loyalty is discussed, and the study framework and related hypotheses are introduced. The research methodology adopted in this study is discussed in Section 3. The analysis and findings are detailed in Section 4, while the results are discussed in Section 5. The study concludes in Section 6 with the implications, limitations, and suggestions for future research.

\section{Literature Review and Hypotheses Development}

The Technology Acceptance Model (TAM) and its adaptation is the widely used model in understanding the impact of antecedents in consumer attitudes and subsequent purchase/repurchase intentions in a technology-driven environment [26-28]. The proposed hypotheses in this study are adapted primarily from the Consumers' Acceptance Model of Chen and Tan [29] (which in turn was developed by expanding TAM) and from Singh [30], who incorporated the self-image variable in TAM. These are discussed in the following sections.

\subsection{Moderating Impact of Brand Loyalty on the Relationship between Trust and Attitude}

Trust has long been regarded as a catalyst for buyer-seller transactions that can provide consumers with high expectations of satisfying exchange relationships [26]. It is defined as the willingness of a party to be vulnerable to the actions of another party based on the expectation that the latter one will perform particular actions, which are important to the former one [31]. In other words, when firms act responsibly, customers are assured, and the "perceived risk with the firm is likely reduced", therefore enhancing the possibility of a positive attitude and behavior by the customer [32].

Attitude, on the other hand, is a psychological tendency that is expressed by evaluating a particular entity with some degree of favor or disfavor [33]. In a marketing context, it is the feeling of an individual (positive or negative) towards the product or brand [28].

A meta-analysis of 128 studies by Wu et al. [31] that employed TAM showed a positive relationship between trust and attitude. However, the moderating impact of brand loyalty on this relationship is unclear, though its impact on attitude is expected to vary with the different levels of loyalty. Social psychology studies have shown an asymmetry between difficulty in creating trust and the ease of its destruction. In other words, establishing trust may be slow and challenging, while losing it may be fast and easy. Conversely, studies on perseverance bias have shown that once people have adopted a belief system, events or happenings that should affect the belief system often result in little or no change in their attitude [34]. It seems the latter is true, as customers who are highly loyal repose greater 
trust, making them impervious to not just inducements but even from clear "breach of trust", as seen from the various scandals, such as the battery gate and Cambridge Analytica. It appears that once trust is established, learning about negative events might be dismissed away as one-off incidents with little or no change in their attitude towards the brand [35]. In line with this argument, we propose the following:

Hypothesis 1a (H1a). The impact of trust on attitude will be significantly greater for high loyal customers as opposed to medium loyal customers.

Hypothesis $\mathbf{1 b} \mathbf{( H 1 b ) . ~ T h e ~ i m p a c t ~ o f ~ t r u s t ~ o n ~ a t t i t u d e ~ w i l l ~ b e ~ s i g n i f i c a n t l y ~ g r e a t e r ~ f o r ~ m e d i u m ~ l o y a l ~ c u s t o m e r s ~}$ as opposed to low loyal customers.

Hypothesis 1c (H1c). The impact of trust on will be significantly greater for high loyal customers as opposed to low loyal customers.

\subsection{Moderating Impact of Brand Loyalty on the Relationship between Self-Image and Attitude}

Self-image is defined as measurable aspects of what one does, how one appears, and what material things one has [36]. The "image" of "self" includes attitudes, perceptions, feelings, and appropriate behavior befitting the situation [37]. Consumers are more likely to buy a brand if they perceive that the brand matches with their self-image. The related self-congruity theory has been tested and retested and continues to be a dominant theory in the realm of consumer behavior and an important predictor of consumer attitudes and purchase intentions [38]. Past studies have demonstrated the impact of self-image congruity on attitude $[39,40]$. While the studies affirm the influence of self-image over brand loyalty, these studies have examined the relationships between the two concepts singularly and as a linear process. In line with Dolich's [41] study, which reveals greater similarity between self-concept congruence and most preferred brands, it is assumed that self-image impact on attitude will be significantly greater for customers with high loyalty levels than medium or low loyalty levels. We, therefore, propose the following hypotheses:

Hypothesis 2a (H2a). Self-image impact on attitude will be significantly greater for high loyal customers as opposed to medium loyal customers.

Hypothesis $\mathbf{2 b} \mathbf{( H 2 b )}$. Self-image impact on attitude will be significantly greater for medium loyal customers as opposed to low loyal customers.

Hypothesis 2c (H2c). Self-image impact on attitude will be significantly greater for high loyal customers as opposed to low loyal customers.

\subsection{Moderating Impact of Brand Loyalty on the Relationship between Quality and Attitude}

In the product literature, quality is a factor for which consumers are willing to pay a higher price, facilitates increased profitability, and is a cause for repeat purchase [42,43]. Zeithaml et al. [44] found that when service quality is high, the customers' behavioral intentions become favorable, and the relationship strengthens. When the service quality is low, the behavioral intentions become low, leading to defection. However, the moderating impact of brand loyalty on the relationship between quality and attitude has not been explicitly studied. However, based on the evidence from studies such as Obermiller and Wheatley [45], which show that the consumer has a greater attitudinal preference for brands with strong prior beliefs in quality than brands with weak prior beliefs in quality, we propose the following: 
Hypothesis 3a (H3a). Quality impact on attitude will be significantly greater for high loyal customers as opposed to medium loyal customers.

Hypothesis $\mathbf{3 b} \mathbf{( H 3 b )}$. Quality impact on attitude will be significantly greater for medium loyal customers as opposed to low loyal customers.

Hypothesis 3c (H3c). Quality impact on attitude will be significantly greater for high loyal customers as opposed to low loyal customers.

\subsection{Moderating Impact of Brand Loyalty on the Relationship between Perceived Ease of Use and Attitude}

Perceived ease of use refers to the degree to which a person believes that using a particular system would be effortless [46]. One of the primary determinants of consumer attitude in TAM is the perceived ease of use. This relationship has been investigated in many contexts, and researchers have invariably found a positive association between the two. However, the moderating impact of loyalty on the relationship between perceived ease of use and attitude is unclear. Similar to other studies, which have shown that the link between loyalty and other variables, such as satisfaction, are not simple, straightforward, or even linear $[47,48]$. It could be assumed that the impact of perceived ease of use on attitude may vary depending upon the strength of loyalty. Going by a similar logic for H3, we posit the following hypotheses:

Hypothesis 4a (H4a). Perceived ease of use impact on attitude will be significantly greater for high loyal customers as opposed to medium loyal customers.

Hypothesis $4 \mathbf{b}(\mathbf{H} 4 \mathbf{b})$. Perceived ease of use impact on attitude will be significantly greater for medium loyal customers as opposed to low loyal customers.

Hypothesis 4c (H4c). Perceived ease of use impact on attitude will be significantly greater for high loyal customers as opposed to low loyal customers.

\subsection{Moderating Impact of Brand Loyalty on the Relationship between Attitude and Repurchase Intention}

Repurchase intentions are defined as the customer's self-reported likelihood of engaging in future repurchase behavior [49]. Zeithaml et al. [44] call it as behavioral intentions whose favorability or unfavourability determines the continuance or defection of a customer with the firm. Again, one of the key relationships in the TAM model is the relationship between attitude and behavioral intention to purchase/repurchase, and studies have invariably found a positive association between the two. However, explicit evidence on the moderating impact of brand loyalty on this relationship is unclear. A seminal, experimental study by Cohen and Houston [50] examined how brand loyal and non-loyal consumers perceived the product attributes of different toothpaste brands, namely Colgate and Crest. Specifically, the study looked at differences in perception between consumers who are loyal (purchased that brand and no other brand) to either of these two leading toothpaste brands and a control group of consumers who have loyalty to some other brand. The results showed only trivial differences in the perception of Colgate and Crest by the control group, while the brand loyalists showed substantial differences, always in the direction of their preferred brand, demonstrating that loyalty moderates the perception of product attributes. In line with Cohen and Houston [50], this study assumes that customers with high loyalty will have a more favorable attitude towards the brand leading to purchase vis-à-vis customers with medium or low loyalty. We, therefore, propose the following hypotheses:

Hypothesis 5a (H5a). Attitude impact on repurchase intention will be significantly greater for high loyal customers as opposed to medium loyal customers. 
Hypothesis $\mathbf{5 b} \mathbf{( H 5 b )}$. Attitude impact on repurchase intention will be significantly greater for medium loyal customers as opposed to low loyal customers.

Hypothesis $5 \mathrm{c}(\mathbf{H 5 c})$. Attitude impact on repurchase intention will be significantly greater for high loyal customers as opposed to low loyal customers.

\section{Proposed Conceptual Model}

Figure 1 shows the conceptual framework proposed in this study. It captures the aforementioned hypotheses in a single comprehensive framework. It allows investigation of multiple theoretical perspectives simultaneously and helps define the boundaries of the field more rigorously, and constitutes a possible future avenue for knowledge to grow in a consistent manner in the field [51].

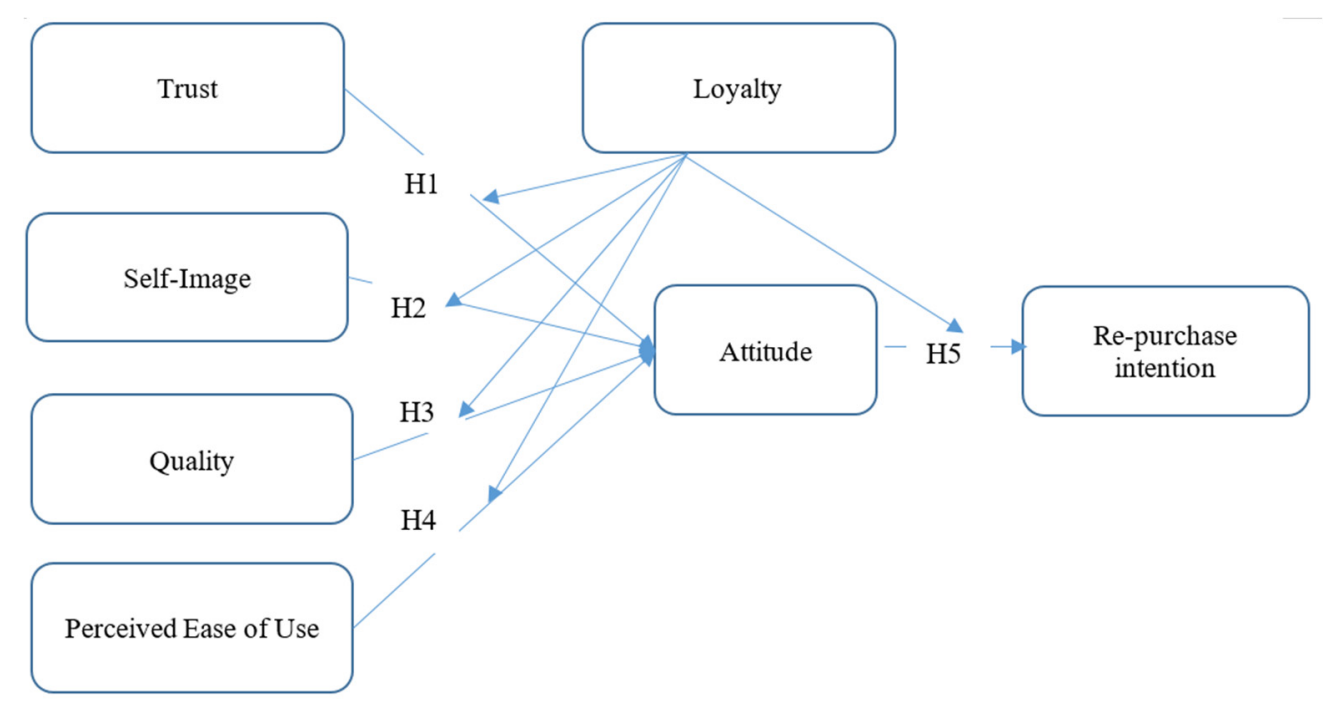

Figure 1. Proposed conceptual model.

\section{Research Methodology}

A survey-based approach was adopted in this study to test the hypotheses proposed in the conceptual framework. The main survey was conducted in the United Arab Emirates (UAE) with self-administered questionnaires distributed between May 2019 and January 2020 to respondents who are users of technology products. Both face-to-face and the online mode was used in this study to increase participation. Past studies have noted that offering multiple modes may improve the response rates [52]. Therefore, in this study a hybrid-mode approach was adopted. Three sets of questionnaires were self-administered online to 1500 networked professionals via Linked-in using Google forms where each respondent was asked to complete all three sets of questionnaires. In the second mode, paper-based surveys were administered face-to-face to two groups of post-graduate students totaling sixty. A total of 355 responses were received reflecting a satisfactory return rate of 23 percent, which appears comparable to similar studies [53,54]. However, we note a $100 \%$ response rate for the face-to-face administered survey as compared to the online mode, as these were directly administered by one of the researchers to post-graduate students who were working professionals Out of a total of 355 responses received, and after checking for incomplete responses, 340 were deemed usable, which included 151 valid responses for high loyalty, 99 for medium loyalty, and 90 for low loyalty groups. In terms of demographics, $57 \%$ of the respondents were male, and $43 \%$ were female, while the average age of the participants was 27 years.

The measures and scales used in this study, as shown in Table 1, were similar to those of Curran and Healy [16]. Content validity of the survey was established using pre-testing of the instrument with three academic peers. The feedback received from the pre-test was integrated into the final 
questionnaire. A pilot-test was carried out prior to the main survey. This pilot-test helped us to evaluate the ease of respondents' understanding of each item and their interpretation in addition to other aspects such as the average completion time.

Table 1. Survey variables and measures.

\begin{tabular}{cc}
\hline Variable & Measure \\
\hline Loyalty & Highly Loyalty, Medium Loyalty, Low Loyalty \\
Attitude (1) & I like the product that I have chosen \\
Attitude (2) & I feel good using the product that I have chosen \\
Attitude (3) & It is pleasant to use the product that I have chosen \\
Repurchase intentions & I am likely to repurchase the product that I have chosen \\
Trust & I trust the product I have chosen \\
Self-image & The product I have chosen expresses my personality \\
Quality & The product I have chosen is of superior quality \\
Perceived ease of use & The product I have chosen is easy to use/access \\
\hline
\end{tabular}

A 7-point point Likert scale ranging from 1 (strongly disagree) to 7 (strongly agree) was used for variables except for loyalty, which was categorized as high, medium, and low loyalty. Following Curran and Healy [16], the participants were asked to think of a technology brand they had purchased in the past and for which they had different degrees of liking, reflecting different loyalty levels. For the high loyalty level, respondents were asked to think of a technology brand that would be their first choice whenever they have a need to buy a technology product. For medium loyalty, respondents were asked to think of a technology brand they buy and like more than other competing brands, but for some reason, they do not always buy. For the low loyalty, respondents were asked to think of a technology brand that they do not really have any like or dislike for, and would be just as happy to buy any competing brand when they have the need for it. Having selected the brand, the respondents were required to answer 16 questions reflecting their attitude strength, the repurchase intentions, strength of loyalty, and the relevance of 11 variables identified from previous studies. The technology products and brands chosen by the participants are shown in Tables 2 and 3.

Table 2. Brands considered.

\begin{tabular}{ccc}
\hline High Loyalty & Medium Loyalty & Low Loyalty \\
\hline & Apple \\
Apple & Dell & Apple \\
Dell & HP & Dell \\
Huawei & Google & Huawei \\
Lenovo & Huawei & JBL \\
Motorola & Lenovo & Lenovo \\
One Plus & Microsoft & Nokia \\
Oppo & Nokia & One Plus \\
Realme & One Plus & Oppo \\
Samsung & Oppo & Samsung \\
Sony & Samsung & Sony \\
Vivo & Sony & Vivo \\
Xiaomi & Vivo & Xiaomi \\
& Xiaomi & \\
\hline
\end{tabular}


Table 3. Products considered.

\begin{tabular}{ccc}
\hline High Loyalty & Medium Loyalty & Low loyalty \\
\hline & Camera & Camera \\
Camera & Computer & Computer \\
Computer & Notebook & Notebook \\
Notebook & Smartphone & Smartphone \\
Smartphone & Smart watch & Smart watch \\
Smart watch & Headphone & LED screen \\
Tablet PC & LED screen & Sound system \\
& Sound system & Tablet PC \\
& Tablet PC & \\
\hline
\end{tabular}

\section{Results}

Before proceeding with testing the hypotheses, we examined the descriptive statistics to identify the relative importance of each variable across the three loyalty groups. The mean and standard deviation of the variables are given in Table 4 .

Table 4. Descriptive statistics.

\begin{tabular}{|c|c|c|c|c|c|c|}
\hline \multirow{3}{*}{ Variables } & \multirow{2}{*}{\multicolumn{2}{|c|}{$\begin{array}{c}\text { Group 1 } \\
\text { High Loyalty }\end{array}$}} & \multirow{2}{*}{\multicolumn{2}{|c|}{$\begin{array}{c}\text { Group 2 } \\
\text { Medium Loyalty }\end{array}$}} & \multirow{2}{*}{\multicolumn{2}{|c|}{$\begin{array}{c}\text { Group } 3 \\
\text { Low Loyalty }\end{array}$}} \\
\hline & & & & & & \\
\hline & Mean & SD & Mean & SD & Mean & SD \\
\hline Trust & 5.95 & 1.29 & 5.34 & 1.56 & 4.97 & 1.66 \\
\hline Self-image & 4.53 & 2.01 & 4.13 & 2.08 & 3.98 & 1.88 \\
\hline Quality & 6.19 & 1.16 & 5.49 & 1.66 & 5.22 & 1.63 \\
\hline Perceived ease of use & 5.91 & 1.38 & 5.42 & 1.62 & 4.92 & 1.74 \\
\hline Attitude & 5.84 & 1.06 & 5.30 & 1.29 & 4.89 & 1.45 \\
\hline Repurchase intention & 5.81 & 1.31 & 5.10 & 1.52 & 4.58 & 1.72 \\
\hline
\end{tabular}

As seen in the Table 4, the mean score (as perceived by the respondents) is significantly greater for high loyalty groups, followed by medium loyalty groups, and low loyalty groups for all the variables considered in the study. Among the antecedents, quality emerged as the variable with the highest mean scores across all three loyalty groups. Trust and perceived ease of use emerged as the second and third most important factors, respectively, for both high and low loyalty groups, while perceived ease of use and trust emerged as the second and third most important factors, respectively, for the medium loyalty group. Self-image emerged as the least important factor across all three loyalty groups. In terms of attitude and repurchase intention, attitude was rated consistently higher than repurchase intention across all the loyalty groups.

Structural equation modeling (SEM) and multi-group analysis were performed to estimate the hypothesized differences in the relationships across different loyalty groups [15]. IBM AMOS 25 software was used for the analysis. However, before proceeding with the test of hypotheses, it was important to ensure that there were significant differences in the overall model across the low, medium, and high loyalty groups. The results of the $\chi^{2}$ difference test are given in Table 5 . As seen in the Table 5, the results are significant $(p<0.05)$ for any pair of loyalty groups, indicating that the overall model is significantly different among the three loyalty groups. 
Table 5. Chi-square difference test of the overall models.

\begin{tabular}{ccc}
\hline High Loyalty and Medium Loyalty & High Loyalty and Low Loyalty & Medium and Low Loyalty \\
\hline$\Delta \chi^{2}$ & $\Delta \chi^{2}$ & $\Delta \chi^{2}$ \\
\hline $11.857^{*}$ & $17.5833^{* *}$ & $26.967^{* * *}$ \\
\hline &
\end{tabular}

To test the differences in the individual relationships and corresponding hypotheses, first, SEM was used to estimate the structural relationships (standardized path coefficients) for each loyalty group. The standardized path coefficients for all three loyalty groups are given in Table 6. As seen in Table 6, the impact of trust on attitude is moderate and significant for all three loyalty groups. Similarly, the impact of attitude on behavioral intention to repurchase is significant for all three loyalty groups, and the strength of the relationship is "moderately high" for high loyalty and low loyalty groups, and "very high" for medium loyalty groups. However, for the impact of self-image on attitude ( $\beta=0.131, p<0.05)$ and for the impact of quality on attitude $(\beta=0.426, p<0.001)$, the relationship is only significant for the low loyalty group, whereas the impact of perceived ease of use on attitude is significant only for the medium loyalty group $(\beta=0.446, p<0.001)$.

Next, to test whether these differences in path coefficients were statistically significant, we compared the unconstrained (or free) model with the constrained model, in which the hypothesized path is constrained to be equal for any two groups, while other paths are set free to vary [15]. For example, to test H1a, the unconstrained model involving high loyalty and medium loyalty groups is compared with the constrained Model b1, in which the path coefficient indicating the strength of the relationship between trust and attitude were kept equal for both the loyalty groups. The $\chi^{2}$ difference was then computed by comparing the constrained model with the unconstrained model; if the results were significant, this meant the selected path (the relationship) was different for the two loyalty groups considered.

The multi-group moderation test results for the individual paths for different loyalty groups are provided in Table 6. As seen in Table 6, there is no statistically significant difference in the strength of the relationships between trust and attitude, and self-image and attitude between any groups, thus rejecting our hypotheses $\mathrm{H} 1(\mathrm{a}, \mathrm{b}$, and $\mathrm{c})$ and $\mathrm{H} 2(\mathrm{a}, \mathrm{b}$, and $\mathrm{c})$. For the relationship between quality and attitude (H3), a statistically significant difference was observed between medium loyalty (Group 2) and low loyalty (Group 3) $\left(\Delta \chi^{2}=10.214, p<0.01\right)$, and between high loyalty (Group 1) and low loyalty (Group 3) $\left(\Delta \chi^{2}=3.941, p<0.05\right)$. However, both the hypotheses, H3b and H3c, were not supported because it was contrary to our proposed hypotheses. For H3b, the relationship was found to be stronger for the low loyalty group than the medium loyalty group, and for $\mathrm{H} 3 \mathrm{c}$, the relationship was found to be stronger for the low loyalty group than the high loyalty group. No significant difference was observed between high and medium loyalty groups $\left(\Delta \chi^{2}=2.079, p=0.149\right)$, hence rejecting hypothesis H3a. Next, for the relationship between perceived ease of use and attitude (H4), a statistically significant difference was observed between high and medium loyalty groups $\left(\Delta \chi^{2}=9.175, p<0.01\right)$, and between medium and low loyalty groups $\left(\Delta \chi^{2}=10.740, p<0.01\right)$. While H4b was supported, H4a was not supported as it was contrary to our proposed hypotheses. Furthermore, H4c was not supported as no significant difference was observed between high and low loyalty groups $\left(\Delta \chi^{2}=0.121, p=0.728\right)$. Finally, for the relationship between attitude and intention to purchase (H5), a statistically significant difference was observed as hypothesized only for the medium and low loyalty groups $\left(\Delta \chi^{2}=3.888, p<0.05\right)$, hence supporting H5b. No significant difference was observed between high and medium loyalty groups $\left(\Delta \chi^{2}=1.289, p=0.256\right)$ and between high and low loyalty groups $\left(\Delta \chi^{2}=0.954, p=0.329\right)$, thus rejecting hypotheses $\mathrm{H} 5 \mathrm{a}$ and $\mathrm{H} 5 \mathrm{c}$, respectively. Table 7 summarizes the hypotheses test results. 
Table 6. Chi-square difference test for the relationships between the variables across different loyalty groups.

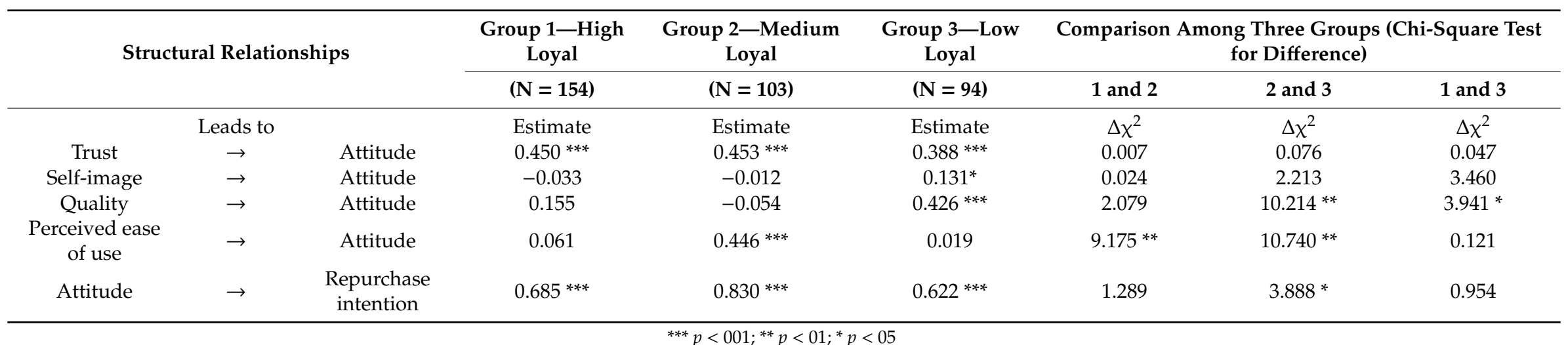


Table 7. Summary of hypotheses test results.

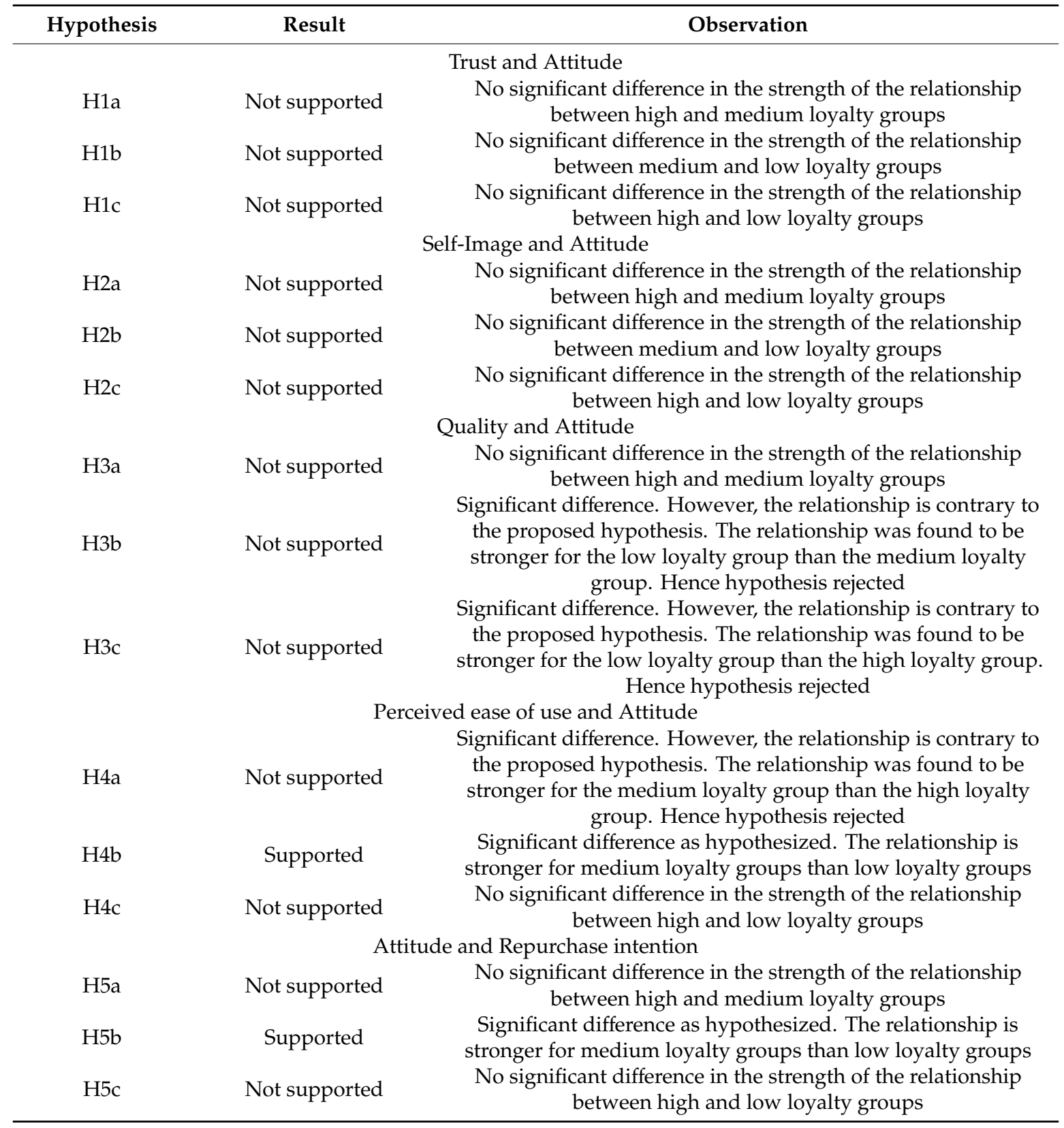

\section{Discussion of Results}

The results of $\mathrm{H} 1$ shows the influence of trust on attitude does not differ based on customer loyalty levels. Trust is, therefore, a necessary precursor in the formation of attitude regardless of the levels of loyalty. In other words, breach of trust could adversely affect the brand throughout its loyalty continuum, including for brands with high customer loyalty. This may seem counterintuitive to the recent evidence from the battery gate, Cambridge Analytica, and emission scandal, wherein breach of trust had little or no change on the consumer attitude towards the brand. Yet, it could be argued that this could be because these may be considered by customers as one-off incidents and that any repeated events of breach of trust could lead to an adverse and irreversible effect on the consumer attitude towards the brand. The results also provide empirical evidence that trust is critical as consumers move through levels of loyalty development $[55,56]$. Therefore, new brands and existing brands looking to strengthen their consumer loyalty should not compromise on trust. 
Similarly, to H1, the results of $\mathrm{H} 2$ show that the influence of self-image on attitude also does not differ across the three different levels of loyalty. Moreover, a very low (strength) and non-significant relationship (except for low loyalty groups) show that customers appear not to lay much emphasis on congruence of their self-image with the technology brands. The low but significant relationship for low loyal customers may be because they indulge in purchases of products from superior brands to gratify their self-image feelings. Overall, still, the lack of any meaningful influence of self-image on attitude across different loyalty groups could be because of the lack of novelty or symbolic benefit in the technological products, which does not provide them with the motivation to express themselves through the possession or adoption of technology products. This is not surprising given that technology brands are increasingly offering less differentiated product offerings. Further, technological products are replete with utilitarian benefits, which makes them be considered more as day-to-day productivity tools than something which allows one to express themselves. Moreover, in the context of this study, UAE is a country that enjoys high per capita income and where consumers have the opportunity to acquire the latest, best, and most luxurious products and/or services, which are construed more as strong symbols for self-image congruence than technology products. For instance, possessing a Lamborghini or a Mercedes G-class SUV with a unique number plate may be more of a status symbol than an iPhone. Perhaps in the context of a different country, the results may be different and could be a part of future studies.

Unlike $\mathrm{H} 1$ and $\mathrm{H} 2$, the results of $\mathrm{H} 3$ show that the importance of quality for creating a positive attitude towards the brand is more critical for brands with consumers in the lower levels of the loyalty spectrum. For medium and high loyalty customer groups, quality was found to have no impact on their attitude towards the brand. This could be explained from the premises of perseverance bias, a tendency to cling to one's initial belief even after receiving new information that contradicts or disconfirms the basis of that belief [34]. This could well explain why a brand such as Samsung was able to bounce back stronger even after a major quality setback with its Note7 smartphone because Note7 users had been Samsung's most loyal users [19]. It also explains the actions of Netflix amid an increase in demand during COVID-19 to lower the streaming quality of its content to its service in Europe to reduce the strain on internet service providers [57]. In sum, the findings show that variation in quality may not affect the attitude of their loyal customer base and that loyal customers provide a safety net in the case of any quality issue that arises.

The results of $\mathrm{H} 4$ also provide critical insights on the role of perceived ease of use on customer attitude towards the product or brand. The heterogeneity in the influence of perceived ease of use on consumer attitudes across different loyalty levels shows that the result is not systemic as conceived in TAM. Contrary to our hypotheses, perceived ease of use was found to have a lower and non-significant influence on the attitude of high loyal customer segments and for low loyal customer segments. For brands looking to attract one time or impulsive buyers, perceived ease of use may not be a concern. For high loyal customer groups, perceived ease of use no longer influences their attitude because, by default, they expect it to be there. Like quality, this shows that even if the perceived ease of use goes down for brands with a loyal customer base, for example, with the addition of new features or application or drastic change in form factor or layout in technology products/services, it may not affect customer attitude that adversely. This could well explain why Instagram managed to keep and grow its active users despite having undergone several updates and layout changes in recent years, which did not go well with their users. However, an interesting finding is a significant relationship between perceived ease of use and attitude for medium loyalty customer groups. In other words, ease of use is critical for brands looking to strengthen their customer brand loyalty and maneuver their medium loyal customers towards greater loyalty. Such brands should invest more in making their products more convenient and easier to use.

Finally, in the case of $\mathrm{H} 5$, while there was no surprise in the fact that consumer attitude positively impacts repurchase intention in line with TAM, the interesting finding is that the strength of this 
relationship is greater for medium loyal groups. In other words, brands with medium loyal customers are poised to gain more from a unit increase in attitude.

\section{Implications and Conclusions}

Business sustainability is adversely impacted by the dwindling number of customers due to the shifts in the spending behaviors, preferences, and new market dynamics in these pandemic times. Many established businesses have gone bankrupt and many more are teetering on the edge of the precipice. Business sustainability resonates globally across all types of businesses, be it a multinational corporation or a small business, a private or public enterprise, it is the same everywhere and the survival of any business is inextricably linked to its customers and their loyalty to the brand.

The study examined the heterogeneity in the relationship between consumer attitudes, its antecedents, and repurchase intention across three different levels of loyalty (high, medium, and low) and found the levels of loyalty have a moderating impact on the relationships. The contributions of this study are manifold. First, the study supports the increasing calls in the literature to empirically examine the moderating impact of loyalty as opposed to its direct or mediating impact in consumer attitude formation and subsequent repurchase intention $[9,15,16]$ (. Given that none of the previous studies have explored the moderating role of loyalty across these three different loyalty groups, the findings of this study are both novel and significant. It also complements other studies in the domain, such as customer loyalty and brand switching intention [5]. Further, given the fact that the brands considered by the respondents are global brands, we believe the findings have generalizability beyond UAE.

Practitioners in the UAE and elsewhere could use the findings to better understand and manage customer attitudes, and subsequent purchase/repurchase intention depending on the levels of loyalty development they may be in. The findings have great significance for marketers in devising strategies for converting low loyalty groups to high loyalty groups. For instance, trust is having a positive impact on attitude across all three loyalty groups and shows that firms should not compromise on trust. Marketers are, therefore, strongly advised to engage in trust-building measures both at a product and company level to reduce the likelihood of customers changing their strong trust beliefs into distrust and defection to other brands.

The results also shed insights for practitioners on the strategy that firms must take to maneuver their customers through the different levels of loyalty. For instance, with the exception of ease of use, all other antecedents (trust, self-image, and quality) are critical in developing a positive consumer attitude towards the product/brand among low loyalty groups. In the case of medium loyalty customer segments, the critical antecedents of attitude are trust and ease of use, whereas, in the case of high loyalty customer segments, trust is the main antecedent of attitude. Breach of trust of loyal customers as evidenced from the increasing number of scandals could be the reason why consumers are feeling less loyal to brands today, and why firms are losing loyal customers faster today to competition $[13,14]$.

Firms could accordingly invest their time, money, and effort to change the levers (trust, quality, self-image, and ease of use) to achieve the desired attitudes towards the product/brand belonging to different customer loyalty segments. The study also shows that having a loyal customer base is still a holy grail in today's fast-changing, competitive, technology-driven world as it makes them impervious to quality issues as well as issues related to ease of use. However, this also means that brands can exploit their high loyal customers, given their perseverance bias. For instance, lowering quality attributes, such as the speed of the product or service (e.g., Apple, Netflix), may not lower consumer attitude because loyal customer segments are likely to have developed a belief system (in line with perseverance bias) that any events or happenings (positive or negative) that should affect the belief system often result in little or no change in their attitude.

The study has some limitations. First, the data for this study was collected from both online and face-to-face participants. The difference in the mode of data collection could have an impact on the results. Second, the data for this study was mostly gathered from UAE, a country that enjoys high per capita income and where consumers have the opportunity to acquire the latest, best, and most 
luxurious products and/or services. A similar study conducted in a low-income country may have yielded different results. Third, the sample size was relatively small, especially for medium and low loyalty groups, again a concern for generalizability. Fourth, only four antecedents of customer attitude were considered in this study. Finally, the study was conducted for technology products and not services. Future studies could, therefore, expand the framework to include more antecedents of consumer attitude. Furthermore, future studies could use the study framework and design to test the moderating effects of loyalty using a large-scale study in other countries as well for non-technology products. Further, future studies could adapt and apply the framework to understand the moderating impact of brand loyalty on technology services such as internet services, mobile applications, etc.

Despite the limitations, we believe our approach and findings can encourage additional research into understanding consumer perceptions, attitudes, and behavioral intention across different loyalty groups and contribute towards the theoretical advancement of brand loyalty literature.

Author Contributions: Conceptualization, S.R.; methodology, S.R.; software, Sreejith Balasubramanian; validation, S.B.; formal analysis, S.B.; writing-original draft preparation, S.R.; writing-review \& editing, S.R., S.B.; All authors have read and agreed to the published version of the manuscript.

Funding: This research received no external funding.

Acknowledgments: Grateful acknowledgement is made to Professor Abdullah Abonamah, Abu Dhabi School of Management, for his valuable suggestions, and to Dr. Muhammad U. Tariq, Abu Dhabi School of Management for his support to this project.

Conflicts of Interest: The authors declare no conflict of interest.

\section{References}

1. Financial Times. Sustainable Businesses Should Be 'Long-Term Greedy'. 2018. Available online: https: //www.ft.com/content/bd30c5ec-20a9--11e9-a46f-08f9738d6b2b (accessed on 28 July 2020).

2. Kiatkawsin, K.; Sutherland, I. Examining Luxury Restaurant Dining Experience Towards Sustainable Reputation of the Michelin Restaurant Guide. Sustainability 2020, 12, 2134. [CrossRef]

3. Majerova, J.; Sroka, W.; Krizanova, A.; Gajanova, L.; Lazaroiu, G.; Nadanyiova, M. Sustainable Brand Management of Alimentary Goods. Sustainability 2020, 12, 556. [CrossRef]

4. Wang, Y.; Chowdhury Ahmed, S.; Deng, S.; Wang, H. Success of Social Media Marketing Efforts in Retaining Sustainable Online Consumers: An Empirical Analysis on the Online Fashion Retail Market. Sustainability 2019, 11, 3596. [CrossRef]

5. Zhang, X.; Ding, X.; Ma, L.; Wang, G. Identifying Factors Preventing Sustainable Brand Loyalty among Consumers: A Mixed Methods Approach. Sustainability 2018, 10, 4685. [CrossRef]

6. Kandampully, J.; Duddy, R. Competitive Advantage Through Anticipation, Innovation and Relationships. Manag. Decis. 1999, 37, 51-56. [CrossRef]

7. Arslan, I.K. The Importance of Creating Customer Loyalty in Achieving Sustainable Competitive Advantage. Eurasian J. Bus. Manag. 2020, 8, 11-20. [CrossRef]

8. Jacoby, J. Brand Loyalty: A Conceptual Definition. In Proceedings of the American Psychological Association, Montreal, QC, Canada, 3-7 September 1971; Volume 6, pp. 655-656.

9. Kim, D.; Lee, S.Y.; Bu, K.; Lee, S. Do VIP Programs Always Work Well? The Moderating Role of Loyalty. Psychol. Mark. 2009, 26, 590-609. [CrossRef]

10. Krishnamurthi, L.; Raj, S.P. An Empirical Analysis of the Relationship between Brand Loyalty and Consumer Price Elasticity. Mark. Sci. 1991, 10, 172-183. [CrossRef]

11. Reicheld, F.F. Loyalty and the Renaissance of Marketing. Mark. Manag. 1994, 2, 10-21.

12. Reicheld, F.F.; Markey, R.G.; Hopton, C. The Loyalty Effect-The Relationship between Loyalty and Profits. Eur. Bus. J. 2000, 12, 134-139.

13. Kumar, V.; Bhagwat, Y. Regaining Lost Customers: The Predictive Power of First-Lifetime Behavior, the Reason for Defection, and the Nature of the Win-Back Offer. J. Mark. 2015, 79, 34-55. [CrossRef]

14. DMA. How to Win Trust and Loyalty. Data and Marketing Association. 2018. Available online: https: //dma.org.uk/uploads/misc/customer-engagment---loyalty-report-26.pdf (accessed on 13 August 2020). 
15. Lee, J.S.; Back, K.J. An Examination of Attendee Brand Loyalty: Understanding the Moderator of Behavioral Brand Loyalty. J. Hosp. Tour. Res. 2009, 33, 30-50. [CrossRef]

16. Curran, J.M.; Healy, B.C. The Loyalty Continuum: Differentiating between Stages of Loyalty Development. J. Mark. Theory Pract. 2014, 22, 367-384. [CrossRef]

17. Business Insider. Apple Will Pay Up to $\$ 500$ Million to End a Lawsuit Claiming It Intentionally Slowed Down iPhones. 2020. Available online: https://www.businessinsider.com/apple-batterygate-500m-lawsuitsettlement-2017-iphone-intentional-slowdown-2020--3 (accessed on 13 August 2020).

18. BBC. Volkswagen: The Scandal Explained. 2015. Available online: https://www.bbc.com/news/business34324772 (accessed on 13 August 2020).

19. The Washington Post. How Samsung Moved Beyond Its Exploding Phones. 2018. Available online: https://www.washingtonpost.com/business/how-samsung-moved-beyond-its-exploding-phones/2018/02/ 23/5675632c-182f-11e8-b681--2d4d462a1921_story.html (accessed on 20 August 2020).

20. Digital Information World. Again Another Layout Change: Instagram Users Are Not in the Favor of New Update. 2019. Available online: https://www.digitalinformationworld.com/2019/06/instagram-new-layoutusers-reaction.html (accessed on 18 August 2020).

21. Statista. Number of Monthly Active Instagram Users from January 2013 to June 2018. 2019. Available online: https://www.statista.com/statistics/253577/number-of-monthly-active-instagram-users/ (accessed on 26 July 2020).

22. Marketing Week. Brands Are Losing Out on $£ 774$ bn by Failing to Bridge the 'Self-Esteem Gap'. 2018. Available online: https:/www.marketingweek.com/brands-losing-out-failing-to-bridge-self-esteem-gap/ (accessed on 28 July 2020).

23. Forbes. A Racially Insensitive Product Photo Just Cost H\&M a Major Celebrity Partner. 2018. Available online: https://www.forbes.com/sites/nicolafumo/2018/01/08/a-racially-insensitive-product-photo-just-costhm-a-major-celebrity-partner/\#22c30d607fb3 (accessed on 20 August 2020).

24. EurWeb. H\&M's Profits Plunge Following Racist 'Coolest Monkey' Hoodie Ad. 2018. Available online: https: //eurweb.com/2018/04/01/hms-profits-plunge-following-racist-coolest-monkey-hoodie-ad/ (accessed on 30 July 2020).

25. Statista. Sales of the H\&M Group Worldwide from 2007 to 2019 (in Million U.S. Dollars). 2020. Available online: https://www.statista.com/statistics/252190/gross-sales-of-the-h-und-m-group-worldwide/ (accessed on 26 July 2020).

26. Pavlou, P.A. Consumer Acceptance of Electronic Commerce: Integrating Trust and Risk with the Technology Acceptance Model. Int. J. Electron. Commer. 2003, 7, 101-134.

27. Johar, M.G.M.; Awalluddin, J.A.A. The Role of Technology Acceptance Model in Explaining Effect on e-Commerce Application System. Int. J. Manag. Inf. Technol. 2011, 3, 1-14. [CrossRef]

28. Shukla, A.; Sharma, S.K. Evaluating Consumers' Adoption of Mobile Technology for Grocery Shopping: An Application of Technology Acceptance Model. Vision 2018, 22, 185-198. [CrossRef]

29. Chen, L.D.; Tan, J. Technology Adaptation in e-Commerce: Key Determinants of Virtual Stores Acceptance. Eur. Manag. J. 2004, 22, 74-86. [CrossRef]

30. Singh, D.P. Integration of TAM, TPB, and Self-Image to Study Online Purchase Intentions in an Emerging Economy. Int. J. Online Mark. 2015, 5, 20-37. [CrossRef]

31. Wu, K.; Zhao, Y.; Zhu, Q.; Tan, X.; Zheng, H. A Meta-Analysis of the Impact of Trust on Technology Acceptance Model: Investigation of Moderating Influence of Subject and Context Type. Int. J. Inf. Manag. 2011, 31, 572-581. [CrossRef]

32. Sirdeshmukh, D.; Singh, J.; Sabol, B. Consumer Trust, Value, and Loyalty in Relational Exchanges. J. Mark. 2002, 66, 15-37. [CrossRef]

33. Albarracin, D.; Johnson, B.T.; Zanna, M.P. (Eds.) The Handbook of Attitudes; Lawrence Erlbaum Associates: Mahwah, NJ, USA; London, UK, 2005.

34. Anderson, C.A.; New, B.L.; Speer, J.R. Argument Availability as a Mediator of Social Theory Perseverance. Soc. Cogn. 1985, 3, 235-249. [CrossRef]

35. Cvetkovich, G.; Siegrist, M.; Murray, R.; Tragesser, S. New Information and Social Trust: Asymmetry and Perseverance of Attributions About Hazard Managers. Risk Anal. 2002, 22, 359-367. [CrossRef] [PubMed]

36. Bailey, J.A. Self-Image, Self-Concept and Self-Identity Revisited. J. Natl. Med Assoc. 2003, 95, 383-386. [PubMed] 
37. Schenk, C.T.; Holman, R.H. A Sociological Approach to Brand Choice: The Concept of Situational Self Image. Adv. Consum. Res. 1980, 7, 610-614.

38. Kressmann, F.; Sirgy, M.J.; Herrmann, A.; Huber, F.; Huber, S.; Lee, D.J. Direct and Indirect Effects of Self-Image Congruence on Brand Loyalty. J. Bus. Res. 2006, 59, 955-964. [CrossRef]

39. Liu, F.; Li, J.; Mizerski, D.; Soh, H. Self-Congruity, Brand Attitude, and Brand Loyalty: A Study on Luxury Brands. Eur. J. Mark. 2012, 46, 922-937. [CrossRef]

40. Premayani, W.W.; Ayu, I.G.; Giantari, K.; Kerti, N.N. The Effect of Self Image Congruity and Functional Congruity to Attitudes and Repurchase Intention. IOSR J. Bus. Manag. 2018, 20, 8-11.

41. Dolich, I.J. Congruence Relationships between Self Images and Product Brands. J. Mark. Res. 1969, 6, 80-84. [CrossRef]

42. Abdul-Rahman, M.; Kamarulzaman, Y. The Influence of Relationship Quality and Switching Costs on Customer Loyalty in the Malaysian Hotel Industry. Procedia Soc. Behav. Sci. 2012, 62, 1023-1027. [CrossRef]

43. Jacobson, R.; Aaker, D.A. The Strategic Role of Product Quality. J. Mark. 1987, 51, 31-44. [CrossRef]

44. Zeithaml, V.A.; Berry, L.L.; Parasuraman, A. The Behavioral Consequences of Service Quality. J. Mark. 1996, 60, 31-46. [CrossRef]

45. Obermiller, C.; Wheatley, J.J. Price Effects on Choice and Perceptions Under Varying Conditions of Experience, Information, and Beliefs in Quality. Adv. Consum. Res. 1984, 11, 453-458.

46. Karahanna, E.; Straub, D.W. The Psychological Origins of Perceived Usefulness and Ease-of-Use. Inf. Manag. 1999, 35, 237-250. [CrossRef]

47. Bloemer, J.M.M.; De Ruyter, K. Customer Loyalty in High and Low Involvement Service Settings: The Moderating Impact of Positive Emotions. J. Mark. Manag. 1999, 15, 315-330. [CrossRef]

48. Oliva, T.A.; Oliver, R.L.; Bearden, W.O. The Relationships among Consumer Satisfaction, Involvement, and Product Performance: A Catastrophe Theory Application. Behav. Sci. 1995, 40, 104-132. [CrossRef]

49. Seiders, K.; Voss, G.B.; Grewal, D.; Godfrey, A.L. Do Satisfied Customers Buy More? Examining Moderating Influences in a Retailing Context. J. Mark. 2005, 69, 26-43. [CrossRef]

50. Cohen, J.B.; Houston, M.J. Cognitive Consequences of Brand Loyalty. J. Mark. Res. 1972, 9, 97-99. [CrossRef]

51. Balasubramanian, S.; Shukla, V. Green Supply Chain Management: An Empirical Investigation on the Construction Sector. Supply Chain Manag. Int. J. 2017, 22, 58-81. [CrossRef]

52. Medway, R.L.; Fulton, J. When More Gets You Less: A Meta-Analysis of the Effect of Concurrent Web Options on Mail Survey Response Rates. Public Opin. Q. 2012, 76, 733-746. [CrossRef]

53. Hunt, S.D.; Chonko, L.B. Advertising Education and Successful Advertising Careers: Are They Related? J. Advert. Res. 1987, 27, 43-51.

54. Powers, T.L.; Bendall Valentine, D. Response Quality in Consumer Satisfaction Research. J. Consum. Mark. 2009, 26, 232-240. [CrossRef]

55. Dick, A.S.; Basu, K. Customer Loyalty: Toward an Integrated Conceptual Framework. J. Acad. Mark. Sci. 1994, 22, 99-113. [CrossRef]

56. Oliver, R.L. Whence Consumer Loyalty? J. Mark. 1999, 63, 33-44. [CrossRef]

57. BBC. Netflix to Cut Streaming Quality in Europe for 30 Days. 2020. Available online: https://www.bbc.com/ news/technology-51968302 (accessed on 16 August 2020).

Publisher's Note: MDPI stays neutral with regard to jurisdictional claims in published maps and institutional affiliations.

(C) 2020 by the authors. Licensee MDPI, Basel, Switzerland. This article is an open access article distributed under the terms and conditions of the Creative Commons Attribution (CC BY) license (http://creativecommons.org/licenses/by/4.0/). 